\title{
The earlier, the better: the effects of different administration timepoints of sorafenib in suppressing the carcinogenesis of VEGF in rats
}

\author{
Nan $\mathrm{Li}^{1} \cdot$ Bin Chen ${ }^{1} \cdot$ Run Lin $^{1} \cdot \mathrm{Ni} \mathrm{Liu}^{2} \cdot$ Hai-tao Dai ${ }^{1} \cdot$ Ke-yu Tang ${ }^{1} \cdot$ Jian-yong Yang ${ }^{1} \cdot$ Yong-hui Huang ${ }^{1}$
}

Received: 24 July 2017 / Accepted: 27 November 2017 / Published online: 1 December 2017

(c) The Author(s) 2017. This article is an open access publication

\begin{abstract}
Purpose To investigate the optimal starting time point of sorafenib therapy in suppressing the tumor-promoting effects of VEGF up-regulation, which is frequently found after local therapy in clinical practice.

Methods VEGF was intravenously injected to imitate the evaluated expression after local tumor therapy, such as TACE. A total of $40 \mathrm{SD}$ rats bearing hepatic tumors were randomly divided into four groups and sorafenib was administered at different timepoints: (A) control group: VEGF injection only; (B) initiating sorafenib $72 \mathrm{~h}$ prior to VEGF injection; (C) initiating sorafenib simultaneously with VEGF injection; (D) initiating sorafenib $72 \mathrm{~h}$ post-VEGF injection. The rate of tumor growth, median survival time, expression of VEGF, and microvessel density (MVD), as determined by immunohistochemical (IHC) examination, were compared.

Results The results revealed that the tumor size and median survival time were significantly different between the three sorafenib groups compared to the control group $(p<0.05)$. Median survival times were 19.6 $\pm 1.78,31.2 \pm 6.99,27.4 \pm 4.9$, and $26.5 \pm 4.6$ days in group A, B, C, and D, respectively. Furthermore, there was a difference in statistical significance between the two sorafenib groups $\mathrm{B}$ and $\mathrm{D}(p=0.04)$. Tumors were collected for HE staining and IHC examination. The expression levels of VEGF in B, C, and D were 42.8 $\pm 7.96,71.9 \pm 15.73$, and 73.6 \pm 13.73 , and all of them were significantly lower than that in the control group (88.3 \pm 13.61 ). Furthermore, the level of MVD was 109.2 \pm 8.98 in the control group, which was significantly higher than in the three sorafenib groups $(45.7 \pm 16.92,77.1 \pm 16.29$, and $93.6 \pm 12.87$, all $p<0.05)$. Conclusions According to our results, the most suitable regimen for the administration of sorafenib is before the increased expression of VEGF, which showed a potential advantage for controlling the tumor growth and prolonging the survival time of test animal via inhibiting VEGF-receptor expression through the bifunction of VEGF, and the reduction of tumor angiogenesis.
\end{abstract}

Keywords Liver tumor $\cdot$ Vascular endothelial growth factor $\cdot$ Microvessel density $\cdot$ Sorafenib $\cdot$ Overall survival time

\section{Introduction}

Hepatocellular carcinoma (HCC) is the second most common cause of cancer-related death worldwide, and the liver is considered to be the most frequent site for

Yong-hui Huang

cir.huangyonghui@vip.163.com

1 Department of Interventional Radiology, The First Affiliated Hospital of Sun Yat-sen University, 58th Zhongshan Road II, Guangzhou 510080, People's Republic of China

2 The Central Hospital of Wuhan, Wuhan, People's Republic of China blood-borne tumor metastases [1-3]. Local therapy, such as TACE, is considered to be an effective palliative treatment for patients with intermediate-advanced HCC [4-7]. These treatments only maintain the short-term stability of lesions, however, and provide a limited survival benefit [8]. Vascular endothelial growth factor (VEGF), one of the most potent factors mediating tumor angiogenesis, was markedly elevated in the majority of patients with HCC after local therapy and was considered to be one of the most important factors of tumor residue and recurrence $[9,10]$. To date, the antiangiogenic multikinase inhibitor, sorafenib, blocks the activity of the Raf serine/ threoninekinase and receptor tyrosine kinases, such as VEGFR-2, PDGFR- $\beta$, c-KIT, FLT-3, and RET, resulting 
in the inhibition of tumor proliferation and neovascularization [11]. The efficacy of sorafenib alone in BCLC stage C HCC has been proven [12-14]. However, its partial response was $3.3 \%$ and drug resistance developed in 6.5 months in patients treated with sorafenib [13]. Furthermore, it is not comprehensive enough for BCLC staging in describing the patients' condition that BCLC stage C includes patients with portal vein tumor thrombus (PVTT), while trunk or branch PVTT is not distinguished clearly in this stage. Safety and efficacy of TACE on HCC with portal vein invasion have been proven [15]. Even though sorafenib treatment significantly increased median overall survival (OS) in BCLC B stage, it is not recommended to administer sorafenib in such stage accoding to current guidelines $[4,16]$. In fact, there are no clear taboos for the two kinds of treatments to most patients with stage B and C. Combined therapy, such as TACE + sorafenib, bears hope for better prognosis. Retrospective studies showed that the combination of TACE + sorafenib could be beneficial for patients with intermediate/advanced HCC [17]. A recent study suggested that this combination might be indicated for patients with BCLC stage B HCC [18], but a phase III trial suggested that this approach should only be used in selected patients [13]. Strebel et al. [19] have proposed three models for the combination of TACE + sorafenib: the sequential, interrupted, and continuous models. Meanwhile, we found that different studies have adopted different models and administration times of sorafenib for patients undergoing TACE [20,21]. Apparently, these differences may lead to controversies across these trials [21]. In this study, an animal experiment was performed to investigate the optimal starting time point of sorafenib administration in the combined therapy.

\section{Materials and methods}

\section{Tumor cells and animals}

Walker-256 tumor cells were obtained from the Cell Bank of Sun Yat-sen University Experimental Animal Center and all animals were obtained from the Experimental Animal Center of Sun Yat-sen University. 4-week-old BALB/c nude mice (body weight, $12-15 \mathrm{~g} ; n=2$ ) received injections of tumor cells at a site on the lateral thigh; 5- to 7-week-old male Sprague-Dawley (SD) rats (body weight, 150-200 g; $n=50$ ) were used for intrahepatic tumor inoculation. Animals were housed under specific pathogen-free conditions with an air-conditioned animal cage at a temperature of $23 \pm 3{ }^{\circ} \mathrm{C}$ and a relative humidity of $50 \pm 10 \%$. All experimental protocols involving animals were approved by the animal ethics committee of Sun Yat-sen University.

\section{Establishment of the subcutaneous tumor model}

The Walker 256 carcinosarcoma cells used for the establishment of the liver tumor models were thawed from $-80{ }^{\circ} \mathrm{C}$ and harvested as previously described [22, 23]. The tumor cell suspension was then diluted to $10^{7}$ cells $/ \mathrm{mL}$ with phosphate-buffered saline (PBS, $16.5 \mathrm{mM}$ phosphate, $137 \mathrm{mM}$ $\mathrm{NaCl}$, and $2.7 \mathrm{mM} \mathrm{KCl}$, at $\mathrm{pH}$ 7.4) and the mixture was subcutaneously inoculated into $\mathrm{BALB} / \mathrm{c}$ nude mice at a site on the lateral thigh. About 9 days after tumor cell inoculation, subcutaneous tumors of approximate $1 \mathrm{~cm}$ in diameter could be detected at the injection site.

\section{Establishment of the hepatic cancer model}

Tumor implantation was performed using a previously described method [24-26]. After mincing the subcutaneous tumors from a donor animal into small cubes of about $1.0 \mathrm{~mm}^{3}, \mathrm{SD}$ rats were laparotomized through a midline abdominal incision under intraperitoneal anesthesia with $10 \%$ chloral hydrate at a dosage of $300 \mathrm{mg} / \mathrm{kg}$. The left lateral lobe of the liver was allowed to protrude out of the abdominal cavity and a subcapsular tunnel of a depth about two-third of the lobe thickness was made with ophthalmic tweezers. A solid tumor tissue cube was then inserted into the tunnel and the wound was covered with a small piece of gelfoam (Jinling Pharmaceutical, Nanjing, China). Hemostasis was not a necessity. All experimental rats were subsequently returned to their cages to recover after surgery and regain normal activity the next day.

\section{Experimental treatment}

Ten days after implantation, magnetic resonance imaging (MRI) was used to evaluate the establishment of the liver tumor model. The experimental animals were anesthetized with intraperitoneal injection of chloral hydrate and were then placed on an MRI micro-coil and scanned (Magnetom Avanto 3.0 T; Siemens, Washington, DC) with both $\mathrm{T}_{1} \mathrm{WI}$ and $\mathrm{T}_{2} \mathrm{WI}$ scanning sequences. The scanning parameters were as follows: echo times of $82.0 \mathrm{~ms}$ for $\mathrm{T}_{1} \mathrm{WI}$ and $1.5 \mathrm{~ms}$ for $\mathrm{T}_{2} \mathrm{WI}$; repetition times of $1500 \mathrm{~ms}$ for $\mathrm{T}_{1} \mathrm{WI}$ and $508.7 \mathrm{~ms}$ for $\mathrm{T}_{2} \mathrm{WI}$; reconstructed slice thickness of $5 \mathrm{~mm}$ for both $\mathrm{T}_{1} \mathrm{WI}$ and $\mathrm{T}_{2} \mathrm{WI}$.

Forty SD rats were eligible with liver tumor from the 50 rats and were randomly divided into four groups: Group A (A, $n=10)$ was control group in which the animals received VEGF (20 mg/L, $1 \mathrm{ml} / \mathrm{kg}$, body weight) [27] injection only. Group B (B, $n=10)$ was given a gavage of sorafenib (100 mg/kg, body weight) [28] $72 \mathrm{~h}$ prior to the injection of VEGF. Group C (C, $n=10)$ was given a gavage of sorafenib 
simultaneously with the VEGF injection. Group D (D, $n=10$ ) was given a gavage of sorafenib $72 \mathrm{~h}$ after the VEGF injection. Sorafenib was administered p.o. once daily for 10 days at a dose levels of $100 \mathrm{mg} / \mathrm{kg}$ body weight. Recombinant rat VEGF165 (20 mg per tube; PeproTech, Rocky Hill, NJ) was centrifuged for $30 \mathrm{~s}$ at $1000 \mathrm{rpm}$, dissolved in $100 \mathrm{~mL}$ of deionized water, and diluted with a normal saline solution to the desired concentration. Rats in groups B, C, and $\mathrm{D}$ received one injection of $20 \mathrm{mg} / \mathrm{L}$ VEGF.

\section{Imaging and pathological investigations}

MRI was used to evaluate the development of tumors and ascites $[4,29]$. It was performed to ensure the liver implantation of tumor tissue and to monitor the development of the tumors and ascites 10 days after the administration of sorafenib.

In case of rapid tumor progression, the general condition of the animals, which was defined in terms of the condition of the coat, nutrition intake, and behavior, was assessed daily. Liver tissues were used to analyze and compare the MVD and VEGF levels of rat liver tumor biopsies, and were obtained after the animals died naturally. We used the Leica Microsystems, the rabbit anti-rat VEGF-165 polyclonal antibody (BOSTER, Inc, Wuhan, China), and rabbit anti-rat CD34 polyclonal antibody (BOSTER, Inc, Wuhan, China). Briefly, $4 \mathrm{~mm}$ serial histological sections from formalin-fixed paraffin embedded blocks of tumor tissue were dewaxed in xylene, rehydrated through graded alcohols, immersed in $10 \mathrm{mM}$ Tris and 0.5 M EDTA at $\mathrm{pH} 9.0$, and were finally microwaved twice for $5 \mathrm{~min}$ each. Subsequently, the sections were incubated with $3 \% \mathrm{H}_{2} \mathrm{O}_{2}$ for 10 min to block endogenous peroxidase activity. The sections were then incubated overnight at $4{ }^{\circ} \mathrm{C}$ with the primary antibodies (dilutions: VEGF2, 1:40; CD34, 1:40).

\section{VEGF and microvessel detection and counting}

The level of VEGF protein expression and MVD was independently determined by two senior pathologists blinded to every slide. The number of epithelial cells that exhibited positive cytoplasmic immunoreactivity to VEGF was determined by counting 100 epithelial cells in every slide and five random sights in every section sample were selected to count stained epithelial cells. The tumor vasculature was examined using an average amount of CD34-positive microvessels. Samples were examined by light microscopy and five areas with the highest numbers of stained microvessels were identified as 'hot spots'. For the quantitation of microvessels, we counted each of the five 'hot spots' using a $200 \times$ magnification field and took the average. Any cell or cell cluster showing positive CD34 staining was counted as a vessel, as described in the Weidner method $[10,30]$. No counts were performed in areas of necrosis or inflammation. Sections, for which five 'hot spots' could not be identified, were excluded from further analysis. If two pathologists had significant differences, sections were reviewed again until they reached a consensus.

\section{Statistical analysis}

SPSS 20.0 was used for all analysis. Data are presented as mean $\pm \mathrm{SD}$, and VEGF and MVD comparisons were performed using repeated-measures analysis of variance with Student-Newman-Keuls for the post hoc test. Kaplan-Meier curves were utilized for median survival time, and intergroup comparisons were made using log-rank tests. Spearman's rank correlation coefficients were computed to estimate the correlations of median survival time and VEGF and MVD expression. A $p$ value $<0.05$ was set as the cutoff for statistical significance.

\section{Results}

\section{Growth of detectable tumors in liver}

10 days later after the implantation of tumor tissues, MR routine scanning was utilized to confirm whether or not there was a liver tumor in the SD rat liver (Fig. 1a). The size and location of tumors were recorded from images of decent quality. Detectable tumors, excluding those in the abdominal wall or abdominal cavity, were accepted for the following experiments. 10 days after administration of sorafenib, we used MR scanning to measure tumor size (Fig. 1b; Table 1). The maximum diameter of the tumor was used as an evaluation index.

\section{Medians for survival time}

The median survival times of different groups were $19.6 \pm 1.78,31.2 \pm 6.99,27.4 \pm 4.9$, and $26.5 \pm 4.6$ days in groups A, B, C, and D, respectively (Fig. 2a, b). The results revealed that the survival times were significantly different between groups subjected to sorafenib and the control $(p<0.01)$. Significant differences were also found between groups B and group D $(p=0.04)$. However, groups B and $\mathrm{C}(p=0.09)$ and groups $\mathrm{C}$ and $\mathrm{D}(p=0.69)$ had no statistic differences (Fig. 2a).

\section{Pathological examination}

After the natural death of the experimental animals, we collected the liver tumor specimens to perform HE staining (Fig. 3). As shown in the pictures, the normal lobular architecture disappeared and tumor cells were arranged as 
Fig. 1 a MRI of a rat liver 10 days after tumor tissue implantation. The tumor (red circle) is evident as a slightly hypointense mass in $\mathrm{T}_{1} \mathrm{WI}$ and a slightly hyperintense mass in $\mathrm{T}_{2} \mathrm{WI}$. The size of the tumor was relatively small. $\mathbf{b} \mathrm{T}_{2} \mathrm{WI}$ MRI coronal scans of rats livers from each of the four experimental groups, 10 days after administrating sorifenib. The tumor (red circle) is evident as a slightly hyperintense mass, within which the necrosis area shows a higher signal. The tumors in the liver did not differ significantly in size or morphology among the sorafenib groups at this time point. The hyperintense region in the abdomen suggested significant ascites. $M R I$ magnetic resonance imaging, VEGF vascular endothelial growth factor a

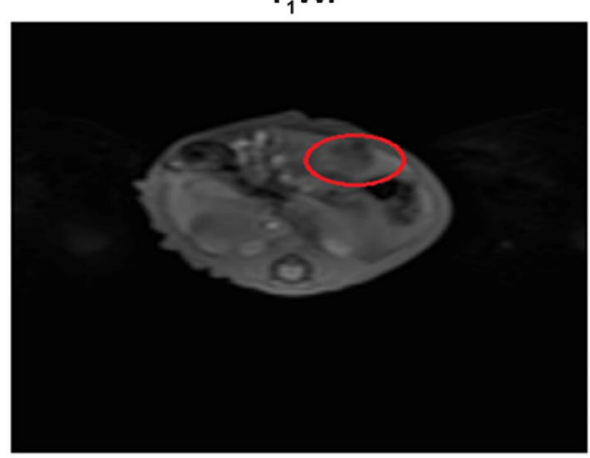

b

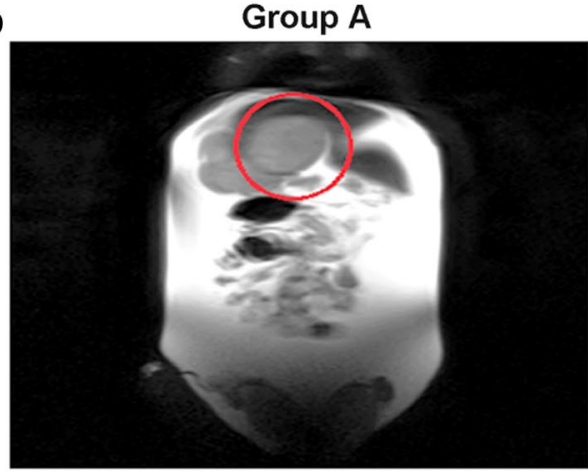

Group C

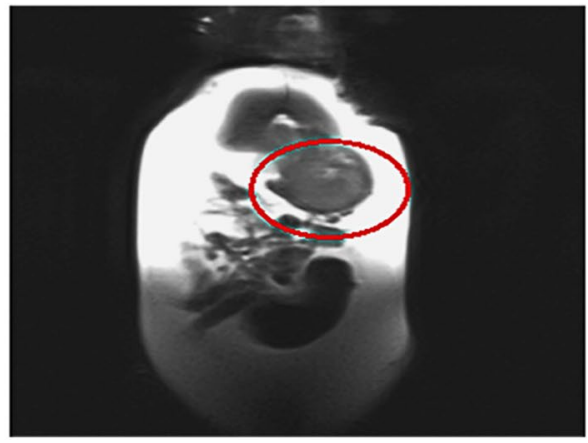

$\mathrm{T}_{2} \mathrm{WI}$

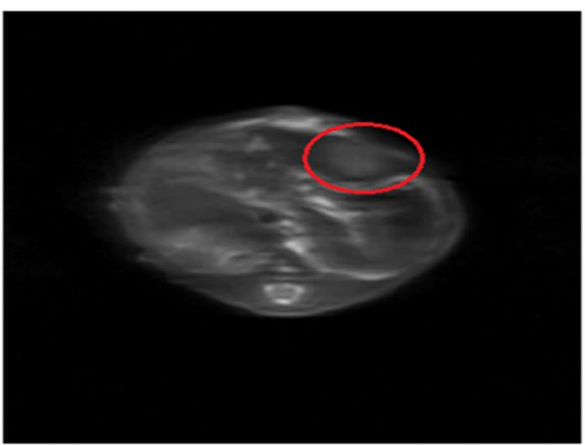

Group B

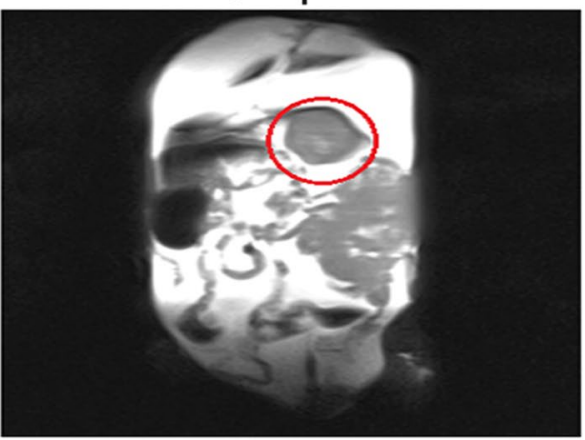

Group D

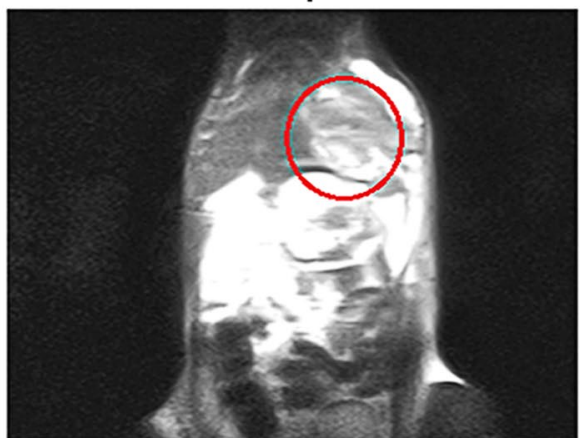

sheets or nests. The tumor cell nuclei had a high frequency of mitoses. Tumor atypical cells were evident, such as dualand even multi-core. A large eosinophilic patch in the visible area was a tumor necrosis area. The tumors did not differ significantly in morphology between the four groups. However, compared with the sorafenib groups, the tumor cells in the control group were smaller and crowded and varied more significantly both in size and shape.

\section{Immunohistochemical methods}

Hepatic cancer VEGF expression appeared as brown staining that was, for the most part, mainly diffusely distributed in the cytoplasm. In the control group, a huge number of VEGF-positive vascular endothelial cells were detected with immunohistochemistry (IHC) (Fig. 4a). The number of samples containing VEGF-positive cells in the control group, $88.3 \pm 13.61$, was higher than those of the sorafenib groups $(p<0.05), 42.8 \pm 7.96,71.9 \pm 15.73$, and $73.6 \pm 13.73$ in groups $\mathrm{B}, \mathrm{C}$, and $\mathrm{D}$, respectively. VEGF was also expressed in a stepwise regression from group B to group D (Fig. 4b), demonstrating that the earlier the feeding time, the more apparent the VEGF inhibition effect of VEGF and the greater the influence on the tumor sorifenib had. CD34-positive cells appeared as brown or dark-brown staining (Fig. 5a). The trend of MVD was just like that of VEGF in the four groups $(109.2 \pm 8.98$, $45.7 \pm 16.92,77.1 \pm 16.29$, and 93.6 \pm 12.87 , respectively) Statistical differences did exist between the control group and sorafenib groups $(p<0.01)$ (Fig. 5b). 
Table 1 Changes in tumor size, as measured by MRI

\begin{tabular}{|c|c|c|c|c|c|c|c|c|}
\hline \multirow[t]{2}{*}{ Rat no. } & \multicolumn{2}{|l|}{ A } & \multicolumn{2}{|l|}{ B } & \multicolumn{2}{|l|}{$\mathrm{C}$} & \multicolumn{2}{|l|}{$\mathrm{D}$} \\
\hline & 10 days & 20 days & 10 days & 20 days & 10 days & 20 days & 10 days & 20 days \\
\hline 1 & 1.4 & 5.4 & 2.0 & 5.2 & 1.9 & 5.0 & 1.8 & 4.9 \\
\hline 2 & 1.2 & -- & 1.8 & 4.9 & 1.7 & 4.2 & 1.5 & 4.6 \\
\hline 3 & 1.9 & -- & 1.5 & 4.6 & 1.9 & 4.9 & 2.1 & 5.0 \\
\hline 4 & 1.8 & -- & 1.7 & 4.7 & 1.8 & -- & 1.9 & 5.3 \\
\hline 5 & 1.2 & -- & 1.4 & 4.2 & 2.0 & 4.9 & 1.6 & 4.8 \\
\hline 6 & 2.0 & 5.7 & 1.9 & 5.4 & 1.6 & 4.4 & 2.0 & 5.1 \\
\hline 7 & 1.7 & 5.6 & 1.8 & 4.6 & 1.9 & 4.8 & 1.8 & 4.5 \\
\hline 8 & 2.1 & -- & 2.2 & 5.8 & 2.1 & 5.1 & 1.9 & 4.7 \\
\hline 9 & 1.9 & -- & 2.0 & 4.1 & 2.0 & 5.2 & 2.1 & -- \\
\hline 10 & 1.6 & 4.9 & 1.5 & 4.3 & 1.7 & 4.7 & 1.5 & 4.1 \\
\hline Mean \pm SD & $1.68 \pm 0.32$ & $5.40 \pm 0.36$ & $1.78 \pm 0.26$ & $4.78 \pm 0.55^{*}$ & $1.86 \pm 0.16$ & $4.80 \pm 0.35^{*}$ & $1.82 \pm 0.23$ & $4.78 \pm 0.36^{*}$ \\
\hline
\end{tabular}

Tumor size is given in $\mathrm{cm}$

${ }^{*} p<0.05$ vs. control group

-- death, $M R I$ magnetic resonance imaging, $S D$ standard deviation, $A$ control group: VEGF injection only, $B$ initiating sorafenib $72 \mathrm{~h}$ prior to VEGF injection, $C$ initiating sorafenib simultaneously with VEGF injection, $D$ initiating sorafenib $72 \mathrm{~h}$ post-VEGF injection

a

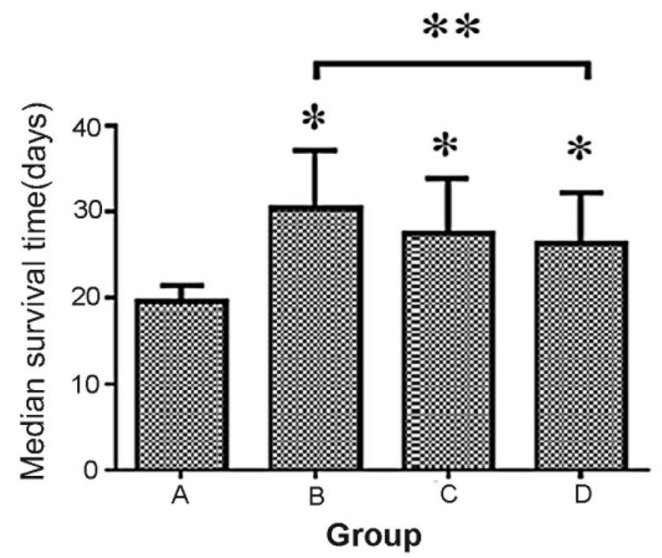

b Survival Function

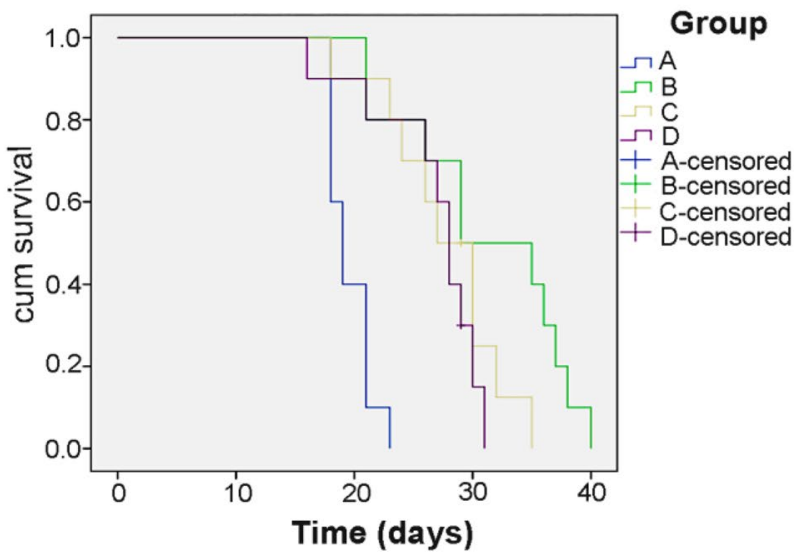

Fig. 2 a Median survival time for the animals from all four groups. $\left({ }^{*} p<0.01\right.$ vs. A, ${ }^{* *} p<0.05$ between two groups shown by horizontal line). b Survival curves for the rats in the four experimental groups. The median survival was 19.6 days in the control group (blue curve),

\section{Associations between median survival time and neoangiogenesis}

VEGF and MVD are commonly utilized to assess the angiogenic activity of tumors: they are consistently associated and their correlational coefficient was 0.875 , which was positive. Using Pearson's correlation analysis of continuous random variables, the Pearson's coefficient product-moment correlation of VEGF and median survival time was 0.78 , which was negative. The correlation between MVD and median survival time was also negative at 0.794 .
31.2 days in group B (green curve), 27.4 days in group C (yellow curve), and 26.5 days in group D (brown curve). The log-rank test revealed significant differences between survival time in the control and all the sorafenib groups $(p<0.01)$

\section{Discussion}

HCC is a cancer with a devastating prognosis [31]. Local therapy, especially TACE, is a preferred palliative treatment for unresectable $\mathrm{HCC}$ and has been proven to prolong overall survival based on high-level evidences [32, 33]. However, these treatments only maintain the stability of the lesion for a short time and provide a limited survival benefit [8]. The pitfalls of local therapy in HCC are tumor residue and recurrence [32], in which sustained angiogenesis is considered to play a critical role [34-36]. Vascular 
Fig. 3 (HE staining; magnification, 200) Group A: VEGF injection only; Group B: initiating sorafenib $72 \mathrm{~h}$ prior to VEGF injection; Group C: initiating sorafenib simultaneously with VEGF injection; Group D: initiating sorafenib $72 \mathrm{~h}$ postVEGF injection. Representative histochemical images showing the cancer morphology of rats with hepatic metastases. Tumor cells with significant atypia are evident and the eosinophilic area shows dead cells
Group A

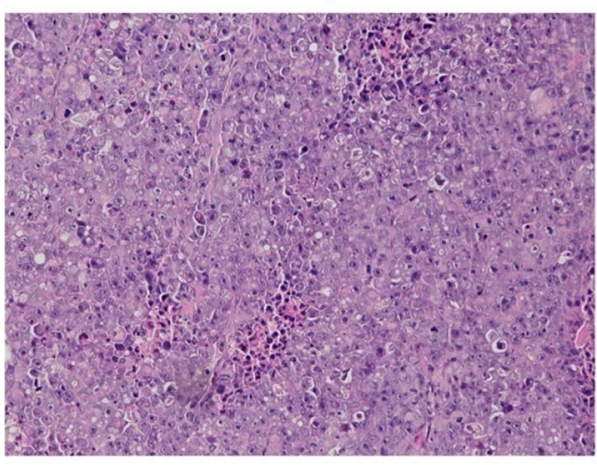

Group C

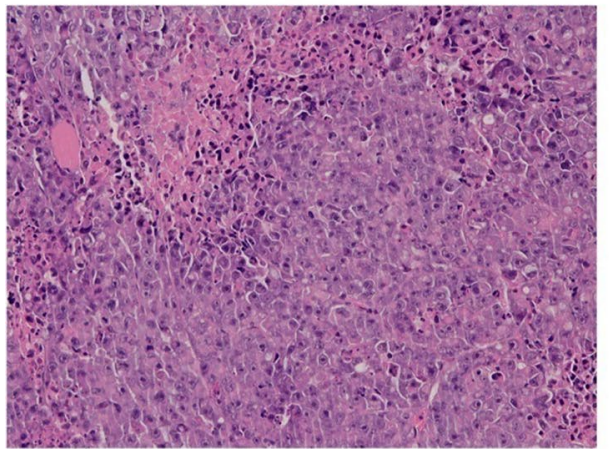

Group B

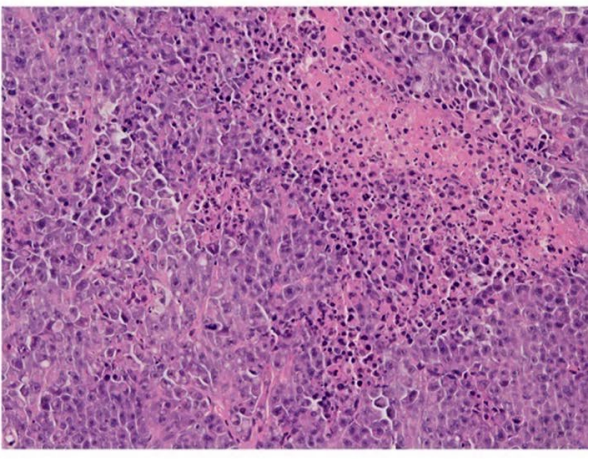

Group D

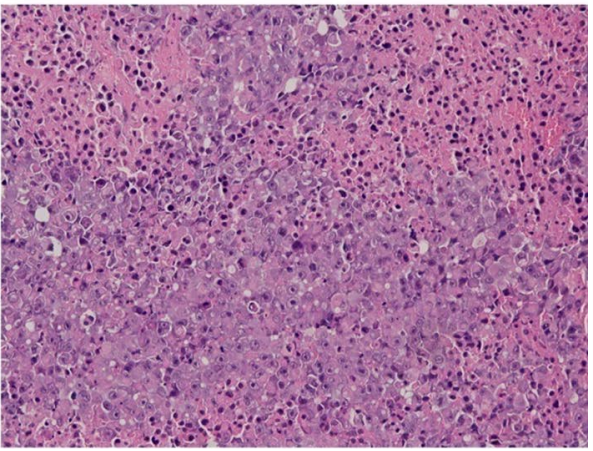

endothelial growth factor (VEGF), one of the most potent factors mediating tumor angiogenesis [37], was markedly elevated in the majority of patients with HCC after local therapy $[9,10]$. In hypervascular tumors characterized by substantial neovascularization [38], high VEGF expression correlates to more malignant biological behavior, including infiltration, recurrence, and metastasis [37]. Among local therapy, TACE is one of the vasculo-occlusive and hypoxic challenges to tumor, and VEGF has more obvious impact on recurrence of residual tumor [39]. A connection has been shown between HIF-1 $\alpha$ levels and VEGF concentration after TACE treatment, and HIF- $1 \alpha$ can increase the liver tumor blood reperfusion up-regulation of VEGF level, thereby leading to the blood reperfusion in residual liver tumor resulting in bad prognosis [34, 35, 40]. In our previous study, we established an orthotopic liver cancer model and determined the dose-response relationship between VEGF and tumorigenesis. Our preliminary experiment proved that exogenous VEGF has an obvious growth promotion effect on liver tumors and that the safest dose is $20 \mathrm{mg} / \mathrm{L}$ [27]. Microvescular density (MVD) is commonly used to assess the angiogenic activity of tumors. MVD is determined by counting CD34-positive vessels, since $\mathrm{CD}-34$ is a vascular endothelial cell proliferation marker and only expressed in the vascular endothelial cells of tumor tissues and not in the vessels of healthy tissues [41].
This characteristic could be used to simulate the effect of VEGF on residual tumor after local therapy.

Sorafenib, as a multikinase inhibitor with antiangiogenic and antiproliferative properties, is the only systemic therapy shown to confer a survival advantage in patients with unresectable advanced HCC [12, 13, 42]. In the pivotal Sorafenib Hepatocellular Carcinoma Assessment Randomized Protocol (SHARP) trial and other randomized controlled trials for patients with advanced HCC, sorafenib treatment significantly increased median overall survival (OS) [13, 43]. Nevertheless, in the current guidelines, sorafenib is still only recommended for stage $\mathrm{C}$ HCC in BCLC and other algorithms [4]. Pawlik et al. [17] found that TACE + sorafenib could improve the prognosis of HCC. Conversely, Kudo, et al. [20] had reported that sorafenib conferred no added benefit. We noticed that differences in timings of antiangiogenic treatment for patients undergoing TACE across these trials were suspected as one important factor of the controversies. Based on our experience, we executed an animal experiment to investigate the effects of sorafenib on liver cancer with VEGF overexpression, and to ascertain valuable information that will improve combination treatments of TACE and sorafenib.

Some literatures have suggested that sorefenib may have a bifunction in suppressing the effects of VEGF and reducing tumor angiogenesis, resulting in increased ischemic 
Fig. 4 a (VEGF, magnification, 400) IHC analysis of VEGF expression in tumor tissues. Group A: VEGF injection only; Group B: initiating sorafenib $72 \mathrm{~h}$ prior to VEGF injection; Group C: initiating sorafenib simultaneously with VEGF injection; Group D: initiating sorafenib $72 \mathrm{~h}$ post-VEGF injection. Positivity for VEGF was identified by dark-brown staining VEGF expression in vascular endothelial cells was high in the control group and lower in the sorafenib groups (A vs. B $p<0.001$, A vs. C $p=0.008$, A vs. $\mathrm{D} p=0.017$ ). b Expressions of VEGF in the four groups $(* p<0.05 \mathrm{vs}$. A. $* * p<0.05$ between the two groups shown by horizontal line). VEGF vascular endothelial growth factor a

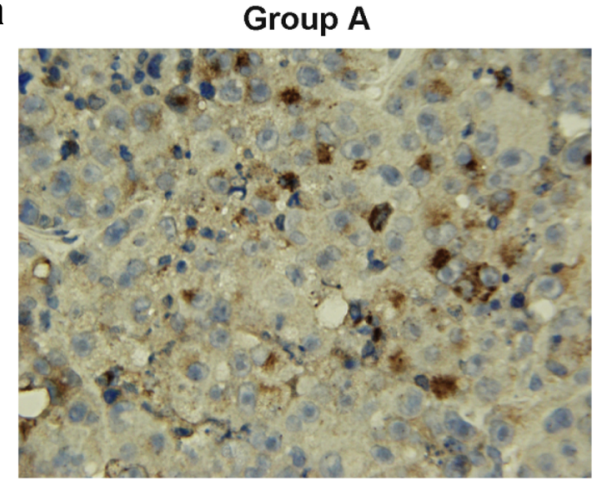

Group C

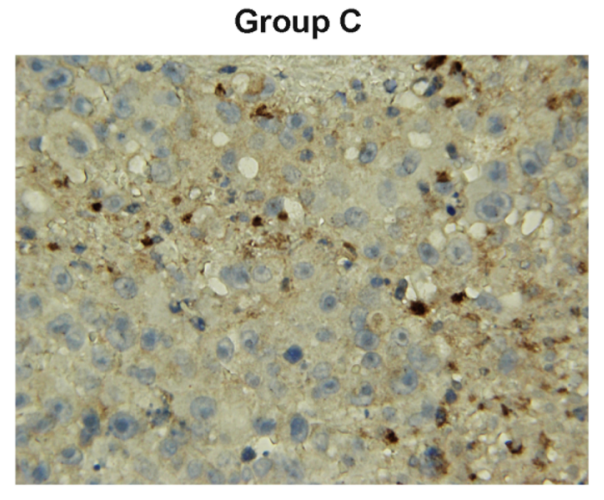

b

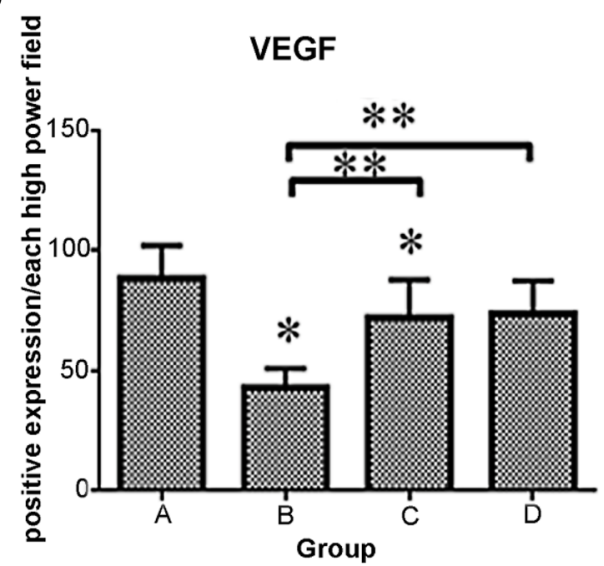

Group B

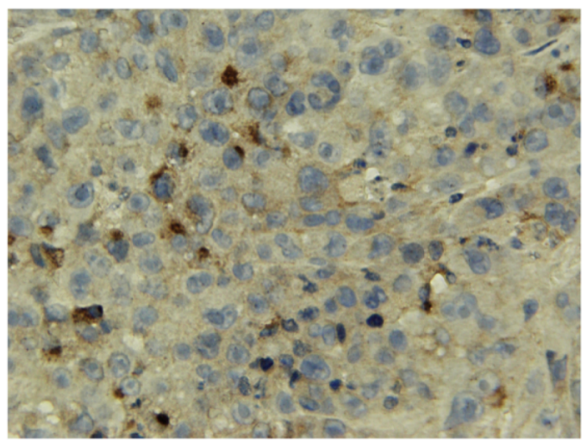

Group D

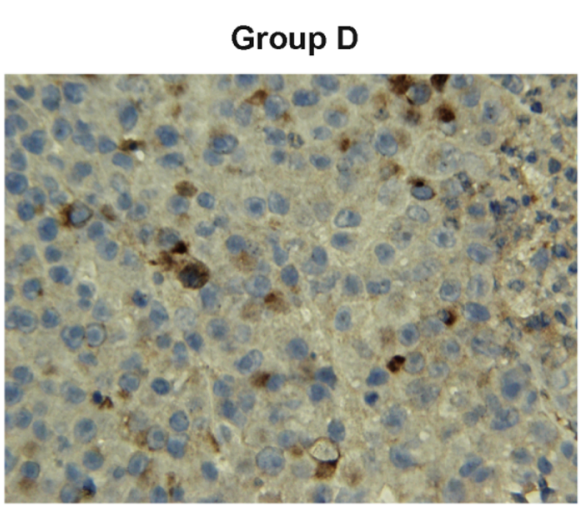

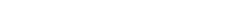

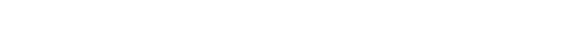

\section{更}


Fig. 5 a (MVD, magnification, 200) IHC analysis for MVD expression in HCC tissue. Group A: VEGF injection only; Group B: initiating sorafenib $72 \mathrm{~h}$ prior to VEGF injection; Group C: initiating sorafenib simultaneously with VEGF injection; Group D: initiating sorafenib $72 \mathrm{~h}$ post-VEGF injection. Positive CD34 cells were identified by brown staining. The abundance of VEGFpositive tumor cells in the control group is clearly higher than that in the experimental group $(p<0.01)$. b Expressions of VEGF in the four groups $(* p<0.05$ vs. A. $* * p<0.05$ between the two groups shown by horizontal line) a

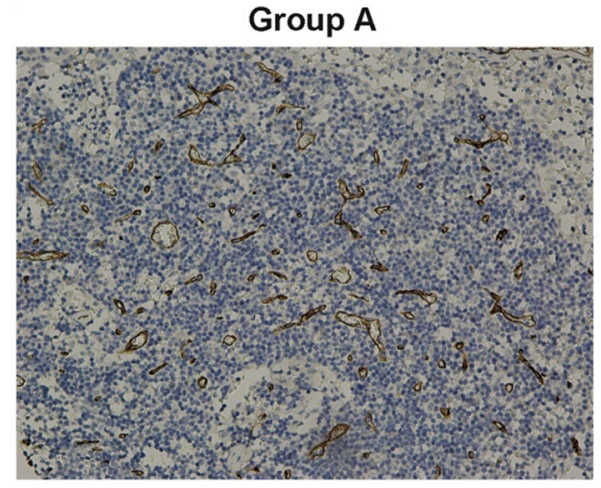

Group C

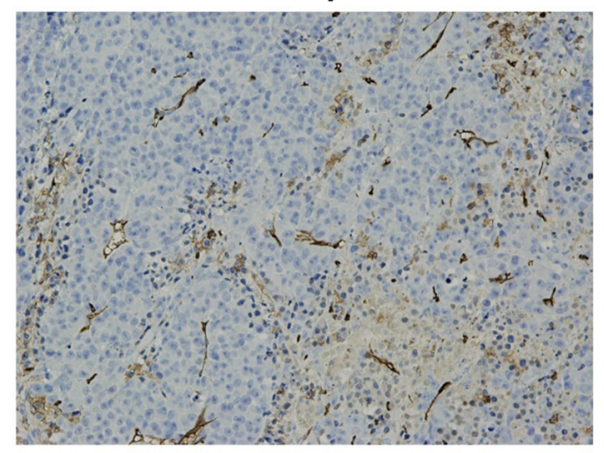

b

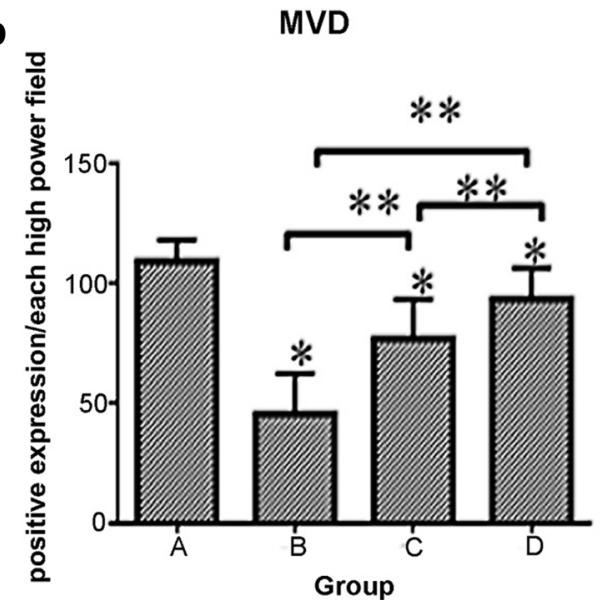

Group B

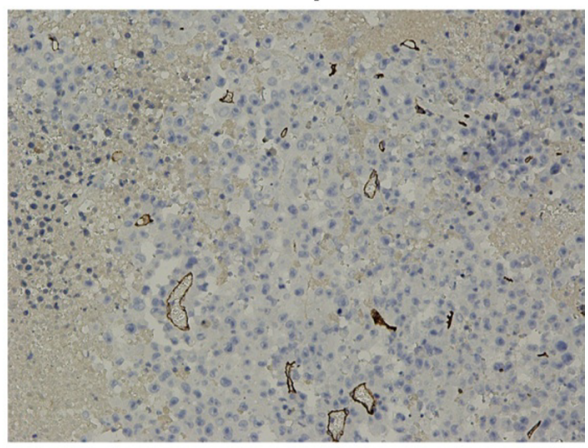

Group D

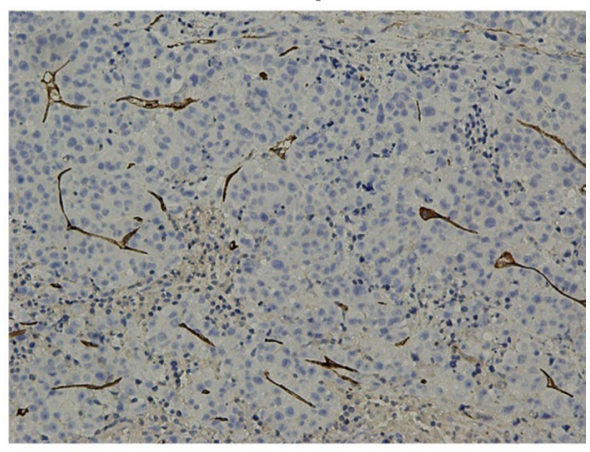

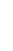
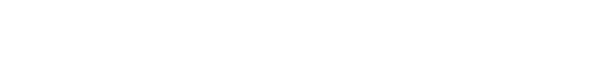
creativecommons.org/licenses/by/4.0/), which permits unrestricted use, distribution, and reproduction in any medium, provided you give appropriate credit to the original author(s) and the source, provide a link to the Creative Commons license, and indicate if changes were made.

\section{References}

1. Torre LA, Bray F, Siegel RL, Ferlay J, Lortet-Tieulent J, Jemal A (2015) Global cancer statistics, 2012. CA Cancer J Clin 65(2):87108. https://doi.org/10.3322/caac.21262

2. Ferlay J, Soerjomataram I, Dikshit R, Eser S, Mathers C, Rebelo M, Parkin DM, Forman D, Bray F (2015) Cancer incidence and mortality worldwide: sources, methods and major patterns in GLOBOCAN 2012. Int J Cancer 136(5):E359-E386. https://doi. org/10.1002/ijc.29210

3. Kodera Y, Fujitani K, Fukushima N, Ito S, Muro K, Ohashi N, Yoshikawa T, Kobayashi D, Tanaka C, Fujiwara M (2014) Surgical resection of hepatic metastasis from gastric cancer: a review and new recommendation in the Japanese gastric cancer treatment guidelines. Gastric Cancer Off J Int Gastric Cancer Assoc Jpn Gastric Cancer Assoc 17(2):206-212. https://doi.org/10.1007/ s10120-013-0299-X

4. Bruix J, Sherman M (2011) Management of hepatocellular carcinoma: an update. Hepatology 53(3):1020-1022. https://doi. org/10.1002/hep.24199

5. Yamada R, Sato M, Kawabata M, Nakatsuka H, Nakamura K, Takashima S (1983) Hepatic artery embolization in 120 patients with unresectable hepatoma. Radiology 148(2):397-401. https:// doi.org/10.1148/radiology.148.2.6306721

6. Zhao J, Zhang H, Wei L, Xie S, Suo Z (2017) Comparing the long-term efficacy of standard and combined minimally invasive procedures for unresectable HCC: a mixed treatment comparison. Oncotarget 8(9):15101-15113. https://doi.org/10.18632/ oncotarget.13145

7. Minagawa M, Makuuchi M (2006) Treatment of hepatocellular carcinoma accompanied by portal vein tumor thrombus. World $\mathrm{J}$ Gastroenterol 12(47):7561-7567

8. Collaborators: Llovet JM DM, Lencioni R, Di Bisceglie AM, Galle PR, Dufour JFGT, Raymond E, Roskams T, De Baere T, Ducreux M, Mazzaferro VMB (2012) EASL-EORTC clinical practice guidelines: management of hepatocellular carcinoma. J Hepatol 56(4):908-943. https://doi.org/10.1016/j.jhep.2011.12.001

9. Li X, Feng GS, Zheng CS, Zhuo CK, Liu X (2004) Expression of plasma vascular endothelial growth factor in patients with hepatocellular carcinoma and effect of transcatheter arterial chemoembolization therapy on plasma vascular endothelial growth factor level. World J Gastroenterol 10(19):2878-2882

10. Wang B, Xu H, Gao ZQ, Ning HF, Sun YQ, Cao GW (2008) Increased expression of vascular endothelial growth factor in hepatocellular carcinoma after transcatheter arterial chemoembolization. Acta Radiol (Stockholm Sweden 1987) 49(5):523-529. https://doi.org/10.1080/02841850801958890

11. Bruix J, Raoul JL, Sherman M, Mazzaferro V, Bolondi L, Craxi A, Galle PR, Santoro A, Beaugrand M, Sangiovanni A, Porta C, Gerken G, Marrero JA, Nadel A, Shan M, Moscovici M, Voliotis D, Llovet JM (2012) Efficacy and safety of sorafenib in patients with advanced hepatocellular carcinoma: subanalyses of a phase III trial. J Hepatol 57(4):821-829. https://doi.org/10.1016/j. jhep.2012.06.014

12. Llovet JM, Ricci S, Mazzaferro V, Hilgard P, Gane E, Blanc JF, de Oliveira AC, Santoro A, Raoul JL, Forner A, Schwartz M, Porta C, Zeuzem S, Bolondi L, Greten TF, Galle PR, Seitz JF, Borbath I, Haussinger D, Giannaris T, Shan M, Moscovici M, Voliotis D, Bruix J (2008) Sorafenib in advanced hepatocellular carcinoma. N Engl J Med 359(4):378-390. https:// doi.org/10.1056/NEJMoa0708857

13. Cheng AL, Kang YK, Chen Z, Tsao CJ, Qin S, Kim JS, Luo R, Feng J, Ye S, Yang TS, Xu J, Sun Y, Liang H, Liu J, Wang J, Tak WY, Pan H, Burock K, Zou J, Voliotis D, Guan Z (2009) Efficacy and safety of sorafenib in patients in the Asia-Pacific region with advanced hepatocellular carcinoma: a phase III randomised, double-blind, placebo-controlled trial. Lancet Oncol 10(1):25-34. https://doi.org/10.1016/s1470-2045(08)70285-7

14. Rimassa L, Pressiani T, Boni C, Carnaghi C, Rota Caremoli E, Fagiuoli S, Foa P, Salvagni S, Cortesi E, Chiara Tronconi M, Personeni N, Bozzarelli S, Chiara Banzi M, Fanello S, Romano Lutman F, Giordano L, Santoro A (2013) A phase II randomized dose escalation trial of sorafenib in patients with advanced hepatocellular carcinoma. Oncologist 18(4):379-380. https://doi. org/10.1634/theoncologist.2012-0221

15. Lu XJ, Dong J, Ji LJ, Luo JH, Cao HM, Xiao LX, Zhou J, Ling CQ (2016) Safety and efficacy of TACE and gamma knife on hepatocellular carcinoma with portal vein invasion. Gut 65(4):715-716. https://doi.org/10.1136/gutjnl-2015-310292

16. Nishikawa H, Takeda H, Tsuchiya K, Joko K, Ogawa C, Taniguchi H, Orito E, Uchida Y, Osaki Y, Izumi N (2014) Sorafenib therapy for BCLC stage B/C hepatocellular carcinoma; clinical outcome and safety in aged patients: a multicenter study in Japan. J Cancer 5(7):499-509

17. Pawlik TM, Reyes DK, Cosgrove D, Kamel IR, Bhagat N, Geschwind JF (2011) Phase II trial of sorafenib combined with concurrent transarterial chemoembolization with drug-eluting beads for hepatocellular carcinoma. J Clin Oncol 29(30):3960 3967. https://doi.org/10.1200/jco.2011.37.1021

18. Huang Y, Chen B, Liu N, Li N, Dao H, Chen W, Yang J (2017) Overall survival in response to sorafenib with transarterial chemoembolization for BCLC stage B hepatocellular carcinoma: propensity score analysis. Int J Clin Pharmacol Ther 55(6):498-508. https://doi.org/10.5414/cp202787

19. Strebel BM, Dufour JF (2008) Combined approach to hepatocellular carcinoma: a new treatment concept for nonresectable disease. Expert Rev Anticancer Ther 8(11):1743-1749. https:// doi.org/10.1586/14737140.8.11.1743

20. Kudo M, Imanaka K, Chida N, Nakachi K, Tak WY, Takayama T, Yoon JH, Hori T, Kumada H, Hayashi N, Kaneko S, Tsubouchi H, Suh DJ, Furuse J, Okusaka T, Tanaka K, Matsui O, Wada M, Yamaguchi I, Ohya T, Meinhardt G, Okita K (2011) Phase III study of sorafenib after transarterial chemoembolisation in Japanese and Korean patients with unresectable hepatocellular carcinoma. Eur J Cancer (Oxford England 1990) 47(14):2117-2127. https://doi.org/10.1016/j.ejca.2011.05.007

21. Abou-Alfa GK (2011) TACE and sorafenib: a good marriage? J Clin Oncol 29(30):3949-3952. https://doi.org/10.1200/ jco.2011.37.9651

22. Vicentino C, Constantin J, Aparecido Stecanella L, Bracht A, Yamamoto NS (2002) Glucose and glycogen catabolism in perfused livers of Walker-256 tumor-bearing rats and the response to hormones. Pathophysiology 8(3):175-182

23. Pigatto MC, Roman RM, Carrara L, Buffon A, Magni P, Dalla Costa T (2017) Pharmacokinetic/pharmacodynamic modeling of etoposide tumor growth inhibitory effect in Walker-256 tumorbearing rat model using free intratumoral drug concentrations. Eur J Pharm Sci 97:70-78. https://doi.org/10.1016/j.ejps.2016.10.038

24. Vicentino C, Constantin J, Bracht A, Yamamoto NS (2002) Long-chain fatty acid uptake and oxidation in the perfused liver of Walker-256 tumour-bearing rats. Liver 22(4):341-349

25. Zhang Y, Li M, Wei L, Zhu L, Hu S, Wu S, Ma S, Gao Y (2013) Differential protein expression in perfusates from metastasized rat livers. Proteom Sci 11(1):37. https://doi. org/10.1186/1477-5956-11-37 
26. Guo WJ, Li J, Chen Z, Zhuang JY, Gu WH, Zhang L, Pang J, Lu $\mathrm{CH}$, Zhang WZ, Cheng YF (2004) Transient increased expression of VEGF and MMP-1 in a rat liver tumor model after hepatic arterial occlusion. Hepatogastroenterology 51(56):381-386

27. Liu N, Yang J, Huang Y, Chen B, Chen W, Li J (2015) Vascular endothelial growth factor accelerates establishment of a model of hepatic metastasis in Walker-256 tumor-bearing rats. Am J Med Sci 349(3):234-239. https://doi.org/10.1097/ maj.0000000000000359

28. Liu L, Cao Y, Chen C, Zhang X, McNabola A, Wilkie D, Wilhelm S, Lynch M, Carter C (2006) Sorafenib blocks the RAF/MEK/ ERK pathway, inhibits tumor angiogenesis, and induces tumor cell apoptosis in hepatocellular carcinoma model PLC/PRF/5. Cancer Res 66(24):11851-11858. https://doi.org/10.1158/00085472.can-06-1377

29. Cheng D, Xu H, Hua R, Xu K, Lv W, Lu X, Du H, Zhang Q (2015) Comparative study of MRI manifestations of acute and chronic Budd-Chiari syndrome. Abdom Imaging 40(1):76-84. https://doi. org/10.1007/s00261-014-0193-y

30. Weidner N, Semple JP, Welch WR, Folkman J (1991) Tumor angiogenesis and metastasis-correlation in invasive breast carcinoma. N Engl J Med 324(1):1-8. https://doi.org/10.1056/ nejm199101033240101

31. Siegel RL, Miller KD, Jemal A (2016) Cancer statistics, 2016. Ca Cancer J Clin 66(1):7

32. Camma C, Schepis F, Orlando A, Albanese M, Shahied L, Trevisani F, Andreone P, Craxi A, Cottone M (2002) Transarterial chemoembolization for unresectable hepatocellular carcinoma: meta-analysis of randomized controlled trials. Radiology 224(1):47-54. https://doi.org/10.1148/radiol.2241011262

33. Llovet JM, Bruix J (2003) Systematic review of randomized trials for unresectable hepatocellular carcinoma: chemoembolization improves survival. Hepatology 37(2):429-442. https://doi. org/10.1053/jhep.2003.50047

34. Kirsch M, Schackert G, Black PM (2004) Metastasis and angiogenesis. Cancer Treat Res 117:285-304

35. Gupta MK, Qin RY (2003) Mechanism and its regulation of tumorinduced angiogenesis. World J Gastroenterol 9(6):1144-1155

36. Patel N, Harris AL, Gleeson FV, Vallis KA (2012) Clinical imaging of tumor angiogenesis. Future Oncol (London England) 8(11):1443-1459. https://doi.org/10.2217/fon.12.136
37. Kaseb AO, Hanbali A, Cotant M, Hassan MM, Wollner I, Philip PA (2009) Vascular endothelial growth factor in the management of hepatocellular carcinoma: a review of literature. Cancer 115(21):4895-4906. https://doi.org/10.1002/cncr.24537

38. Hsieh MY, Lin ZY, Chuang WL (2011) Serial serum VEGF-A, angiopoietin-2, and endostatin measurements in cirrhotic patients with hepatocellular carcinoma treated by transcatheter arterial chemoembolization. Kaohsiung J Med Sci 27(8):314-322. https:// doi.org/10.1016/j.kjms.2011.03.008

39. Suzuki H, Mori M, Kawaguchi C, Adachi M, Miura S, Ishii H (1999) Serum vascular endothelial growth factor in the course of transcatheter arterial embolization of hepatocellular carcinoma. Int J Oncol 14(6):1087-1090

40. Li Y, Zhai Z, Liu D, Zhong X, Meng X, Yang Q, Liu J, Li H (2015) CD105 promotes hepatocarcinoma cell invasion and metastasis through VEGF. Tumour Biol 36(2):737-745. https:// doi.org/10.1007/s13277-014-2686-2

41. Pereira T, Dodal S, Tamgadge A, Bhalerao S, Tamgadge S (2016) Quantitative evaluation of microvessel density using CD34 in clinical variants of ameloblastoma: an immunohistochemical study. J Oral Maxillofac Pathol 20(1):51-58. https:// doi.org/10.4103/0973-029x.180929

42. Nowak AK, Chow PK, Findlay M (2004) Systemic therapy for advanced hepatocellular carcinoma: a review. Eur J Cancer (Oxford England 1990) 40(10):1474-1484. https://doi. org/10.1016/j.ejca.2004.02.027

43. Pawarode A, Tangkijvanich P, Voravud N (2000) Outcomes of primary hepatocellular carcinoma treatment: an 8-year experience with 368 patients in Thailand. J Gastroenterol Hepatol 15(8):860-864

44. Yu C, Bruzek LM, Meng XW, Gores GJ, Carter CA, Kaufmann SH, Adjei AA (2005) The role of Mcl-1 downregulation in the proapoptotic activity of the multikinase inhibitor BAY 43-9006. Oncogene 24(46):6861-6869. https://doi.org/10.1038/ sj.onc. 1208841

45. Dufour JF, Hoppe H, Heim MH, Helbling B, Maurhofer O, SzucsFarkas Z, Kickuth R, Borner M, Candinas D, Saar B (2010) Continuous administration of sorafenib in combination with transarterial chemoembolization in patients with hepatocellular carcinoma: results of a phase I study. Oncologist 15(11):1198-1204. https:// doi.org/10.1634/theoncologist.2010-0180 